\title{
MORPHINE INHIBITS CORTISOL AND STIMULATES PROLACTIN SECRETION IN MAN
}

\author{
Athanasios P. Zis, Roger F. Haskett, A. Ariav Albala and Bernard J. Carroll \\ Department of Psychiatry, University of Michigan, Ann Arbor, MI 48109, U.S.A.
}

(Received 16 August 1983; in final form 18 January 1984)

\begin{abstract}
SUMMARY
The role of opioids in endocrine regulation has been the subject of numerous studies. Surprisingly, however, the acute endocrine effects of morphine on basal hormonal levels in man have not been adequately documented. We report here the effects of intravenous morphine $(5 \mathrm{mg})$ on plasma cortisol and prolactin. Fourteen healthy volunteers (nine male, five female) received morphine at $0930 \mathrm{hr}$. Blood samples were collected immediately before and 30, 60, 90,120 and $180 \mathrm{~min}$ after the injection. In six of the male subjects the procedure was repeated with a placebo (normal saline) injection. Morphine stimulated prolactin release. There was a trend for a greater response in females compared to male subjects. Cortisol secretion was markedly suppressed by morphine. In sharp contrast to the results obtained with placebo, cortisol levels following morphine declined progressively at a rate consistent with the half-life of cortisol. This downward trend of cortisol values continued uninterrupted for the duration of the experiment in all 14 subjects. These results are consistent with the presence of an inhibitory opioid mechanism in the human hypothalamopituitary - adrenal axis.
\end{abstract}

Key Words-Morphine; cortisol; prolactin.

\section{INTRODUCTION}

SINCE the discovery of the opiate receptors and endogenous opioid ligands the role of opioids in endocrine regulation has been the subject of numerous investigations. In man most of the evidence is consistent with an inhibitory opioid effect on hypothalamic pituitary - adrenal function (Morley, 1981). This, however, conflicts with the stimulatory effect of the prototypical opiate alkaloid, morphine, on the hypothalamic - pituitary adrenal system of the experimental animal (Meites et al., 1979). Although dosage and/or species differences could account for the discrepancy, the acute effect of morphine on this system in man is in fact poorly documented (Cushman, 1981). We were able to locate only two reports of controlled studies on the acute effect of morphine on human basal hormonal levels. Tolis et al. (1975) reported increased prolactin secretion but no effect on cortisol for $2 \mathrm{hr}$ following the intravenous administration of morphine (10 mg), whereas McDonald et al. (1959) found a mid-day suppression of cortisol 4 and $5 \mathrm{hr}$ after the subcutaneous administration of morphine $(16 \mathrm{mg})$. We now report data indicating clearly that the intravenous administration of morphine $(5 \mathrm{mg})$ inhibits cortisol secretion.

\section{MATERIALS AND METHODS}

Fourteen informed, consenting, healthy volunteers, nine men and five women, $23-38$ yr old were studied. None were receiving medications. The women were studied between days three and five of their menstrual cycle. After an overnight fast they remained supine in bed from $0730 \mathrm{hr}$ until completion of the study. An indwelling catheter was inserted in the antecubital vein at $0830 \mathrm{hr}$ and maintained open by a slow infusion of heparinized 
normal saline. Morphine sulfate $(5 \mathrm{mg}$ in $1 \mathrm{ml}$ ) was injected through the same catheter over $1 \mathrm{~min}$ at $0930 \mathrm{hr}$. In six male subjects the procedure was repeated using a placebo injection (normal saline). At least $48 \mathrm{hr}$ elapsed between studies, and subjects were blind to the sequence. Blood samples were obtained immediately before and $30,60,90,120$ and $180 \mathrm{~min}$ after the injection.

Blood was collected in heparinized tubes and immediately centrifuged. Plasma samples were frozen and stored at $-20^{\circ} \mathrm{C}$. Total plasma corticoids ('cortisol') were measured by the transcortin method of Murphy (1967). Intra- and interassay coefficients of variation were 3.9 and $10.8 \%$ respectively. Plasma prolactin was measured by RIA using antibody and standard donated by the National Hormone and Pituitary Program. Intra- and interassay coefficients of variation were 5.4 and $6.8 \%$ respectively. All plasma samples from a single subject were analyzed in duplicate in the same assay.

Data were analyzed using repeated measures analysis of variance.

\section{RESULTS}

The effect of morphine on prolactin secretion is illustrated in Fig. 1. Morphine stimulated prolactin secretion in both male $(d f=5,40 ; F=3.57 ; p<0.01)$ and female $(d f=5,20 ; F=7.91 ; p<0.001)$ subjects. In contrast, prolactin levels did not change with time following the placebo injection $(d f=5,25 ; F=0.36 ; p=$ N.S.). There was no difference in the prolactin response to morphine between male and female subjects $(d f=$ 1,$12 ; F=1.95 ; p=$ N.S.).

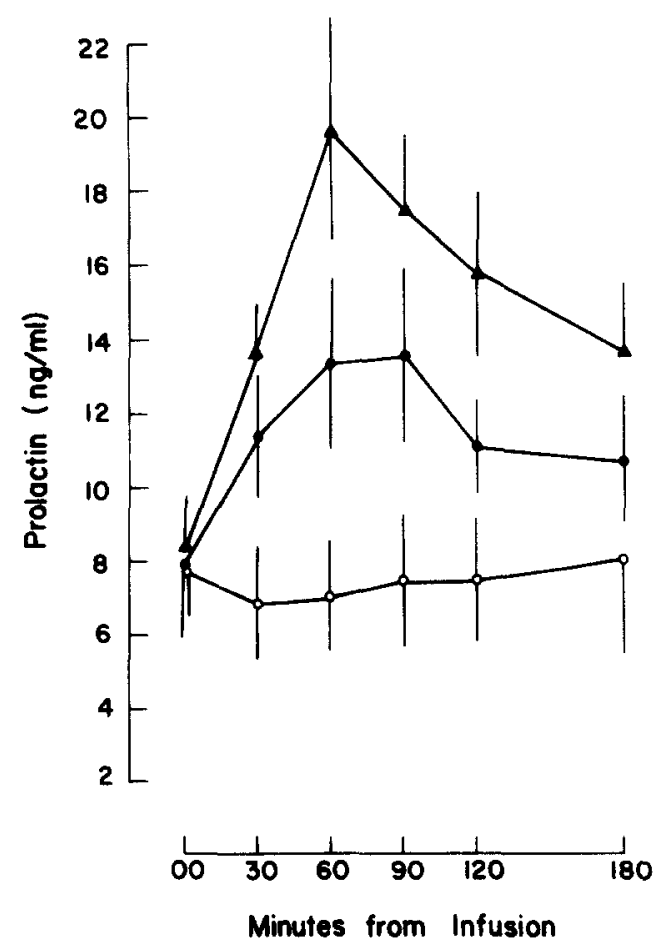

FIG. 1. Prolactin response to morphine in nine male $\longrightarrow$ and five female $\_\longrightarrow$ subjects and to placebo in six male subjects $\bigcirc-$. Data represent mean \pm S.E.M. 
The effect of morphine on cortisol secretion is shown in Fig. 2. Following morphine, plasma cortisol levels declined progressively in both male $(d f=5,40 ; F=38.98$; $p<0.001)$ and female $(d f=5,20 ; F=19.84 ; p<0.001)$ subjects. There was no difference in the cortisol response to morphine between male and female subjects $(d f=$ 1,$12 ; F=0.37 ; p=$ N.S.).

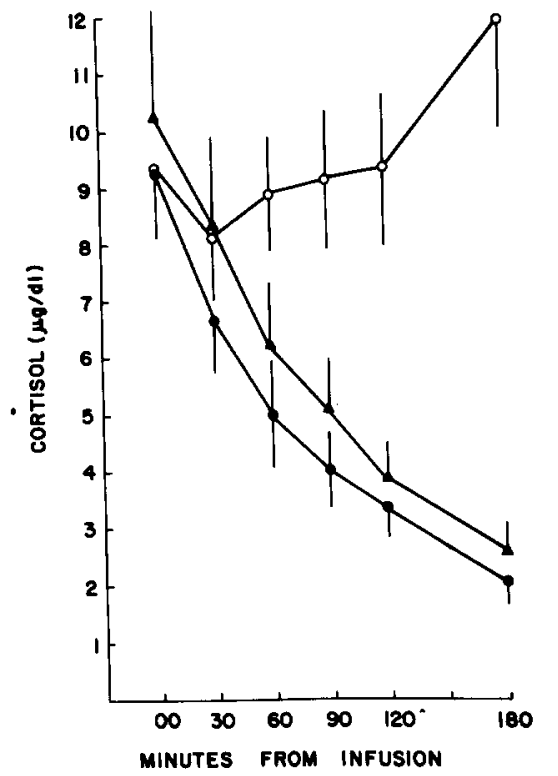

FIG. 2. Cortisol response to morphine in nine male $\longrightarrow$ and five female $\triangle \longrightarrow \Delta$ subjects and to placebo in six male subjects $\bigcirc \longrightarrow$. Data represent mean \pm S.E.M.

\section{DISCUSSION}

The data show that the intravenous administration of $5 \mathrm{mg}$ morphine stimulates prolactin and inhibits cortisol secretion. The observed effect on prolactin secretion is in agreement with an earlier report by Tolis et al. (1975). It is also consistent with the stimulation of prolactin secretion produced by $ß$-endorphin, enkephalin analogues and other opioid peptides (Catlin et al., 1980; von Graffenfried et al., 1978; Stubbs et al., 1978; Degli Uberti et al., 1983). In our experiment, the sequence of the study for the six male subjects receiving both morphine and placebo was morphine followed by placebo. It is unlikely that the observed increment in prolactin release was a non-specific anticipatory or stress effect, since cortisol levels decreased concomitantly.

Compared to men, women exhibit a greater prolactin response to various stimuli, a difference possibly related to the presence of higher estrogen levels in women (Degli Uberti et al., 1983; Bowers et al., 1971; Judd et al., 1976; Carlson et al., 1973). A trend in this direction was observed in the present study. Failure to obtain statistical significance could be attributed to number of subjects studied and/or the fact that our females were studied during the early follicular phase of their menstrual cycle which is characterized by lower estrogen levels. 
The plateau of cortisol values seen after placebo is in agreement with the observations of Weitzman et al. (1971). Using $20 \mathrm{~min}$ sampling they documented the continuous presence of intermittent cortisol rises during this part of the day. Since these individual secretory episodes occur irregularly, the fluctuation in plasma cortisol is not represented in the mean values, which appeared to plateau from $1100 \mathrm{hr}, 3 \mathrm{hr}$ following 'lights on' time. Our time of morphine administration $(0930 \mathrm{hr})$ was also $3 \mathrm{hr}$ after waking.

In contrast to the plateau following placebo, plasma cortisol levels declined progressively after the injection of morphine, at a rate consistent with the half-life of cortisol (Weitzman et al., 1971; Peterson \& Wyngaarden, 1956). Cortisol values continued to decline for the duration of the experiment in all 14 subjects studied. These data clearly indicate that in man morphine suppresses cortisol secretion, an observation consistent with the reported effects of methadone, enkephalin analogues and opiate addiction and withdrawal (Gold et al., 1980; Stubbs et al., 1978; Del Pozo et al., 1980; Eisenman et al., 1961). These data are also in agreement with the reported increases in ACTH and cortisol following the administration of the opiate antagonist, naloxone (Volavka et al., 1979; Morley et al., 1980; Grossman et al., 1982).

Our results differ from those of Tolis et al. (1975), who reported no effect of morphine on cortisol. This discrepancy could be attributed to dose and subject differences. We used a lower dose of morphine. Furthermore, our healthy volunteers served as their own controls whereas in their study morphine and placebo were administered to different subjects admitted for elective surgery. Our results are also at variance with those of McDonald et al. (1959), who did not detect an effect until 4 and $5 \mathrm{hr}$ following the administration of morphine. Differences in dose, route of administration and sampling frequency (they used only hourly samples) could account for their failure to detect an earlier effect.

Morphine could act to decrease plasma cortisol at a number of levels within the hypothalamo-pituitary-adrenal system. Under certain conditions and at high concentrations, certain exogenous opioids can decrease steroidogenesis in adrenal cells in vitro (Gibson et al., 1979; Rácz et al., 1980; Diel et al., 1981). The relevance of these observations to the present data, however, is uncertain. Although we did not measure $\mathrm{ACTH}$, we believe the effect not to be in the adrenals, since the adrenal cortex of acutely morphinized subjects is quite responsive to ACTH (McDonald et al., 1959). Whether morphine exerts an effect directly on the pituitary or acts via the hypothalamus and the limbic system remains to be determined.

We thank R. Edwards, P. Nelson, J. Ritchie, and L. Shapiro for their assistance. This study was supported in part by NIMH Grant No. MH 28794-07.

\section{REFERENCES}

Bowers, C. Y., Friesen, H. G., Hwang, P., Guyda, H. J. \& Folders, K. (1971) Prolactin and thyrotropin release in man by synthetic pyroglutamyl-histidyl-prolinamide. Biochem. biophys. Res. Commun. 45 , $1033-1041$.

Carlson, H. F., Jacobs, L. S. \& Daughaday, W. H. (1973) Growth hormone, thyrotropin and prolactin responses to thyrotropin-releasing hormone following diethylstilbestrol pre-treatment. J. clin. Endocr. Metab. 37, $488-490$. 
Catlin, D. H., Poland, R. E., Gorelick, D. A., Gerner, R. H., Hui., K. K., Rubin, R. T. \& Li, C. H. (1980) Intravenous infusion of B-endorphin increases serum prolactin but not growth hormone or cortisol in depressed subjects and withdrawing methadone addicts. J. clin. Endocr. Metab. 50, $1021-1025$.

Cushman, P. (1981) Neuro-endocrine effects of opioids. Adv. Alcohol Subst. Abuse 1, 77-99.

Degli Uberti, E. C., Trasforini, G., Salvadori, S., Tomatis, R., Margutti, A., Bianconi, M., Rotola, C. \& PANSINI, R. (1983) Prolactin-releasing activity of dermorphin, a new synthetic potent opiate-like peptide in normal human subjects. $J$. clin. Endocr. Metab. 56, $1032-1034$.

Del Pozo, E., Martin-Perez, J., Stadelmann, A., Girard, J. \& Brownell, J. (1980) Inhibitory action of a met-enkephalin on ACTH release in man. J. clin. Invest. 65, $1531-1534$.

Diel, F., Holz, J. \& BETHGE, N. (1981) Failure of somatostatin and ß-endorphin to affect bovine adrenal cortex cells in vitro. Horm. Metab. Res. 13, $95-98$.

Eisenman, A. J., Fraser, H. F. \& Brooks, J. W. (1961) Urinary excretion and plasma levels of 17-hydroxycorticosteroids during a cycle of addiction to morphine. J. Pharmac. exp. Ther. 132, $226-231$.

Gibson, A., Ginsburg, M., Hall, M. \& HaRT, S. L. (1979) The effects of opioid drugs and of lithium on steroidogenesis in rat adrenal cells suspension. Br. J. Pharmac. 65, 671-676.

Gold, P. W., Extein, I., Pickar, D., Ross, R. \& Goodwin, F. K. (1980) Suppression of plasma cortisol in depressed patients by acute intravenous methadone infusion. Am. J. Psychiat. 137, 862-863.

Grossman, A., Gaillard, R. C., McCartney, P., Rees, L. H. \& Besser, G. M. (1982) Opiate modulation of the pituitary - adrenal axis: effects of stress and circadian rhythm. Clin. Endocr. 17, 279-286.

Judd, S. J., Lazarus, L. \& SMYthe, G. (1976) Prolactin secretion by metoclopramide in man. J. clin. Endocr. Metab. 43, 313-317.

McDonald, R. K., Evans, F. T., Weise, V. K. \& PATRick, R. W. (1959) Effect of morphine and nalorphine on plasma hydrocortisone levels in man. J. Pharmac. exp. Ther. 125, $241-247$.

Meites, J., Bruni, J. F., VAn Vugt, D. A. \& SMITH, A. F. (1979) Relation of endogenous opioid peptides and morphine to neuroendocrine functions. Life Sci. 24, $1325-1336$.

Morley, J. E. (1981) The endocrinology of the opiates and opioid peptides. Metabolism 30, $195-209$.

Morley, J. E., Baranetsky, N. G., Wingert, T., Carlson, H. E., Hershman, J. M., Melmed, S., Levin, S. R., Jamison, K. R., Weitzman, R., Chang, R. J. \& VARner, A. A. (1980) Endocrine effects of naloxone-induced opiate receptor blockade. J. clin. Endocr. Metab. 50, 251-257.

Murphy, B. E. P. (1967) Some studies of the protein binding of steroids and their application to the routine micro and ultramicro measurement of various steroids in body fluid by competitive protein-binding radioassay. J. clin. Endocr. Metab. 27, 973-990.

PETERSON, R. E. \& WYNGAARDEN, J. B. (1956) The miscible pool and turnover rate of hydrocortisone in man. J. clin. Invest. 35, 552-561.

Rácz, K., Gláz, E., Kiss, R., Lada, G. Y., Varga, I., Vida, S., Di Glerio, K., Medzihradszky, K., LiCHTWALD, K. \& VECSEI, P. (1980) Adrenal cortex-a newly recognized peripheral site of action of enkephalins. Biochem. biophys. Res. Commun. 97, 1346-1353.

Stubbs, W. A., Delitala, G., Jones, A., Jeffcoate, W. I., Edwards, C. R. W., Ratter, S. J., Besser, G. M., Bloom, S. R. \& Albert, K. G. M. M. (1978) Hormonal and metabolic responses to an enkephalin analogue in normal man. Lancet ii, $1225-1227$.

TOLIS, G., HickEY, J. \& GUYDA, H. (1975) Effects of morphine on serum growth, cortisol, prolactin, and thyroid stimulating hormone in man. J. clin. Endocr. Metab. 41, 797-800.

Volavka, J., Cho, D., Mallya, A. \& Bauman, J. (1979) Naloxone increases ACTH and cortisol levels in man. New Engl. J. Med. 300, 1056- 1057.

von Graffenfried, B. E., Del Pozo, E., Roubicek, J., Krebs, E., Poldinger, W., Burmeister, P. \& KERP, L. (1978) Effects of the synthetic analogue FK 33-824 in man. Nature 272, $729-730$.

Weitzman, E. D., Fukushima, D., Noguera, C., Roffwarg, H., Gallagher, T. F. \& Hellman, L. (1971) Twenty-four hour pattern of the episodic secretion of cortisol in normal subjects. $J$. clin. Endocr. Metab. $33,14-22$. 